\title{
Identification of volatile components form fresh, sun-dried and shade-dried Musa nana Lour. flowers and bracts by Headspace Solid-Phase Microextraction and Gas Chromatography-Mass Spectrometry
}

\author{
Xulong Huang, Liubo Yang, Yuqing Liang, Jin Cui, Xiangpei Wang, Hongmei \\ $\mathrm{Wu}^{*}$
}

Department of Pharmacognosy, Guiyang University of Chinese Medicine, 50, Nanming District, Guiyang City, Guizhou Province, Guiyang 550002, PR China

Email: 1432657649@qq.com,799550947@qq.com,10837419099@qq.com,516260179@ qq.com, wxp0123@126.com, *Correspondence to: whm0425@126.com

Keywords: Musa nana Lour. flower and bract; volatile compounds; identified; different drying conditions; gas chromatography-mass spectrometry (GC-MS).

Abstract. The flower of Musa nana Lour., also named 'XiangJiaohua' in Chinese, is a commonly used herbal drug in traditional Chinese medicine (TCM). Musa nana Lour. flower and bract were usually discarded after banana fruit ripening, which leaded to resource waste and environmental pollution. It can not only protect the environment but also reduce the waste of resources to improve the utilization of the banana (Musa nana Lour.) flower and bract, so we analyzed volatile compounds of fresh, sun-dried and shade-dried Musa nana Lour. flowers and bracts by gas chromatography-mass spectrometry (GC-MS) technique with head-space solid micro-extraction (HS-SPME). The number of volatile ingredients from three kinds of Musa nana Lour. flowers were identified 29, 39 and 43, respectively. Thirteen common constituents were found in all of the three flowers. While three kinds of Musa nana Lour. bracts were identified 30, 36 and 37 volatile ingredients, respectively. In addition, twenties common constituents were found in all of the three bracts. It can be seen the compounds between flowers and bracts in different drying conditions were different apparently. This is the first ever report revealing the differences of volatile components between Musa nana Lour. flowers and bracts in different drying conditions.

\section{Introduction}

Musa nana Lour. is originating in Southeast Asia, including southern China. In China, it is mainly distributed in subtropical regions, such as Guangdong, Guangxi, Fujian, Taiwan, Yunan and Hainan. Its flower is referring the flower or flower bud of Musa nana Lour. And it is also known as banana flower. Banana (Musa nana Lour.) flowers are wastes after picking the ripe banana. Currently, most of them are directly discarded in producing area. Many Asian countries such as Sri Lanka, Malaysia, Indonesia, the Philippines, Laos, Myanmar and other countries make the banana flowers as vegetables, usually by the way of cooking and frying[1]. In India, banana flowers were used as medicine to increase female's breast milk, mitigate dysmenorrhea, and treat diabetes for thousands of years[2]. There are some studies showing that the water, chloroform, ethanol extraction of banana flowers all have significant hypoglycemic and antioxidant activity[3-5]. In China, a research that hypoglycemic effect in diabetic mice with alkaloids from banana stamen was carried out, the result showed that the banana stamen can reduce blood glucose level of alloxan-induced diabetic mice significantly[6]. Someone used supercritical $\mathrm{CO}_{2}$ extraction technology to extract the essential oil of fresh and dried banana bud, and the essential oil was analyzed by GC-MS. There were 13 and 14 compounds identified respectively from fresh and dried banana bud, of which 9 common components[7]. There wasn't any report about the kinds and content of volatile components of banana flowers and bracts whether or not they affected by both the drying methods previous. In order to further improve the utilization of banana flowers and expand the medicinal resources, we analyze the chemical 
composition of volatile substances of fresh, sun-dried and shade-dried Musa nana Lour. flowers and bracts by utilizing GC-MS. We could find out the difference of kinds and content of volatile components of Musa nana Lour. flowers and bracts with variant processing methods, so as to provide the reference for the drying methods of drying for Musa nana Lour. flowers and bracts.

\section{Experimental}

Plant Materials. The flowers and bracts of Musa nana Lour. were collected from Zhangzhou City, Fujian Province in May, 2015 and further identified by Dr. X.P. Wang, Department of Pharmacognosy, Guiyang University of Chinese Medicine, P. R. China. All voucher specimens were deposited in the Department of Pharmacognosy, Guiyang University of Chinese Medicine, P.R. China. The bracts and flowers were cut into small pieces, and they were divided into three parts, respectively. One part of them were put in storage bags, and the bags were kept in the refrigerator at $-20^{\circ} \mathrm{C}$, respectively. And another two parts were dealt with drying in the sun( stored at $30-40^{\circ} \mathrm{C}$ in sunshine to dry) and drying in the shade( were stored at $20-30^{\circ} \mathrm{C}$ in darkness to air dry), respectively.

Solid-phase micro extraction procedure. The flowers and bracts of Musa nana Lour. were accurately weighed $(6.0 \mathrm{~g})$ and placed into $25-\mathrm{mL}$ sample vials from Supelco (Bellefonte, USA), respectively. Then, a 2cm-50/30um DVB-CAR-PDMS Stable Flex fiber (Bellefonte, USA) was used to the headspace above the samples for extracting $40 \mathrm{~min}$ under about $100^{\circ} \mathrm{C}$. then the extraction head was removed from sample vials and immediately inserted onto the GC injection port. The SPME fiber head was hung over the vial for 3 min and then directly desorbed and analyzed.

\section{Gas Chromatography-Mass Spectrometry}

The analyses of gas chromatography was performed on a Hewlett-Packard 6890GC-5973C MSD (Agilent, Palo Alto, CA, U.S.A.) using a ZB-5MSi (5\% phenyl-95\% dimethylpolysiloxane) fused silica capillary column $(30 \mathrm{~m} \times 0.25 \mathrm{~mm} \times 0.25 \mathrm{~mm})$. The oven temperature was programmed as follows: held at $40^{\circ} \mathrm{C}$ for $2 \mathrm{~min}$, adjusted to $270^{\circ} \mathrm{C}$ at a rate of $5^{\circ} \mathrm{C} / \mathrm{min}$, run $48 \mathrm{~min}$. The injector temperature was $250^{\circ} \mathrm{C}$. High-purity helium $(99.999 \%)$ was used as the carrier gas at a flow rate of $1.0 \mathrm{ml} / \mathrm{min}$ with splitless injection.

The mass spectrometer was fitted with an electron ionization source operated at $70 \mathrm{eV}$. The source temperature was $230^{\circ} \mathrm{C}$, and the interface temperature was $280^{\circ} \mathrm{C}$ with a solvent delay of $1.5 \mathrm{~min}$. The emission current was $34.6 \mu \mathrm{A}$, and the multiplier voltage was $1294 \mathrm{~V}$. Mass spectra were recorded from $\mathrm{m} / \mathrm{z}$ 29-450 amu in the full scan mode. Volatile compounds were identified by comparison of mass spectra of the analytes with those of authentic standards from the NIST2005 and Wiley275 libraries. The instrument Chemstation data processing system was used to determine the relative concentrations of the analytes by the peak area normalization method.

\section{Results and Discussion}

The volatile components were isolated and identified by experimental methods and experimental conditions. The relative percentage of compounds were measured by retention index and peak area normalization method. The total ion chromatogram of Musa nana Lour. flower of different drying methods are shown in Fig.1, Fig.2, Fig.3, Fig.4, Fig.5 and Fig.6, and the corresponding volatile compounds are listed in Table 1 and Table 2. A total of 60 volatile components were identified from fresh, sun-dried and shade-dried Musa nana Lour. flowers by GC-MS technology. 43, 29 and 39 components were identified in all of them, respectively. There are 13 collaborative components were found all of three flowers, accounting for $51.178 \%, 79.088 \%$ and $75.325 \%$, separately. A total of 55 volatile components were identified from fresh, sun-dried and shade-dried Musa nana Lour. bracts by GC-MS technology. And 30, 36 and 37 components were identified in all bracts, respectively. There are 20 collaborative components were found all of three bracts, accounting for $63.387 \%, 89.329 \%$ and $84.361 \%$, separately.

As shown in Table 1, the main components of the volatile oil in all flowers are aldehydes and alcohols, while aldehydes, alcohols, ethers and ketones in all bracts. We found that fresh flowers had a 
high content of alkanes than other two kinds of flowers, but the content of aldehydes were higher in sun-dried flower than others and ketones had a higher content in shade-dried flower. In Table 2, we have obtained that fresh bracts had a high content of olefins than other two kinds of bracts, but the content of alcohols and ketones were higher in sun-dried bracts than others and aldehydes and ketones had a higher content in shade-dried bracts. All the flowers and bracts in this research were from the same plant, however, there was a big difference between their volatile components. The volatile compositions of flowers and bracts with different drying methods are also variant, so we can choose different drying methods for our objective. Banana flowers are rich in fiber, and the vitamin and anthocyanin of fiber can eliminate free radicals in the body to delay senility and prevent and reduce the incidence of cardiovascular disease and cancer after being absorbed. In addition, banana flower also contains plenty of protein, fat, sugar, amino acids, trace elements, etc.

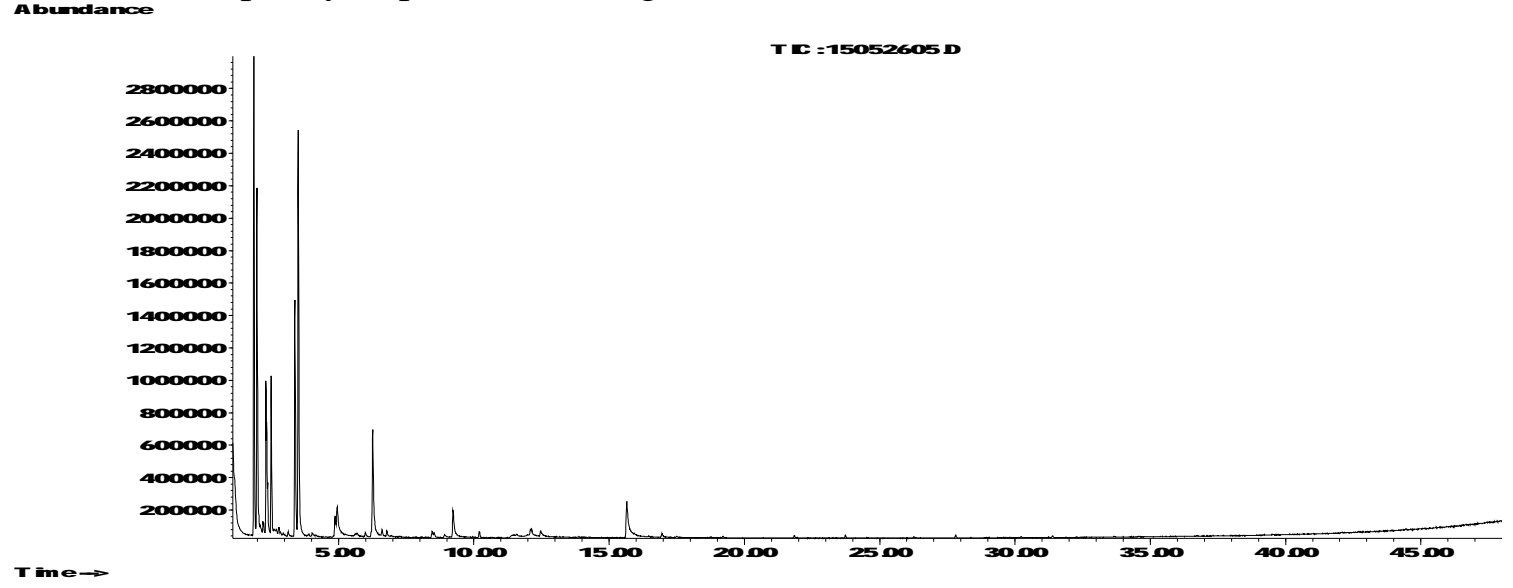

Time(min)

Fig1. TIC of volatile components extracted from Musa nana Lour. flower drying in the sun.

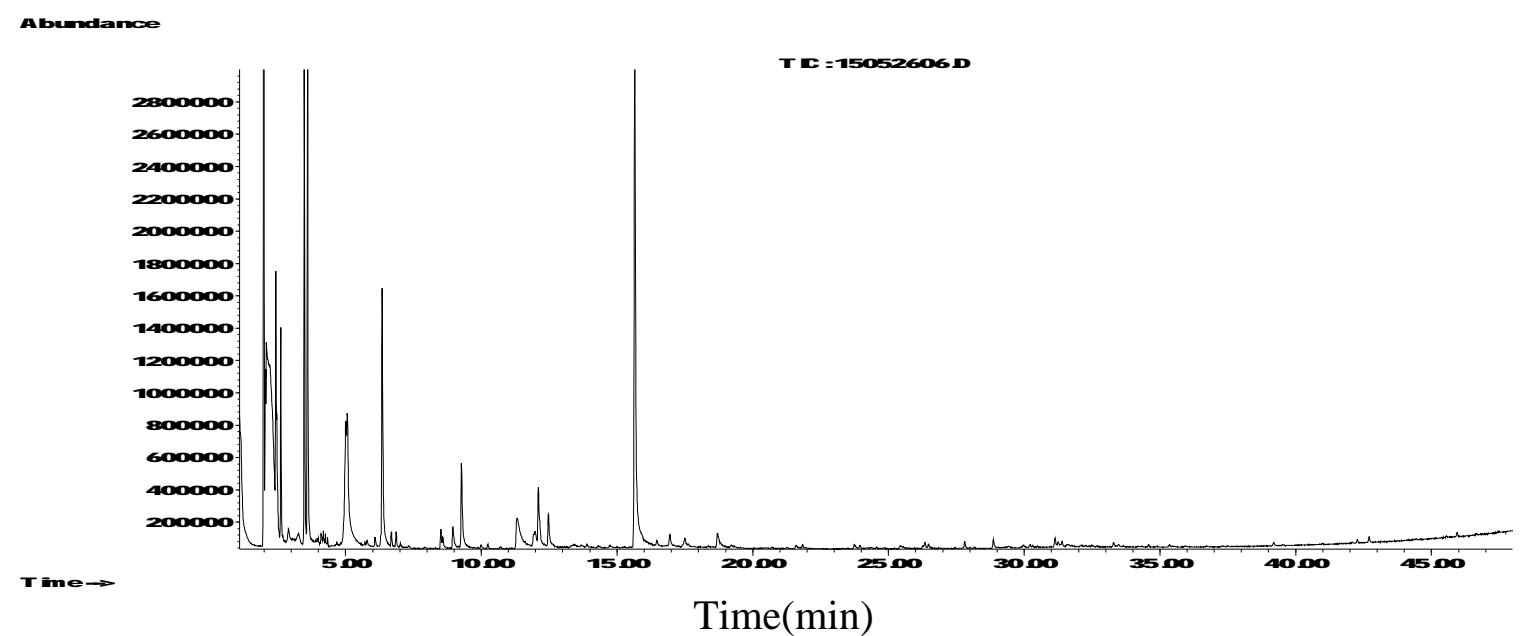

Fig2. TIC of volatile components extracted from Musa nana Lour. flower drying in the shade. 


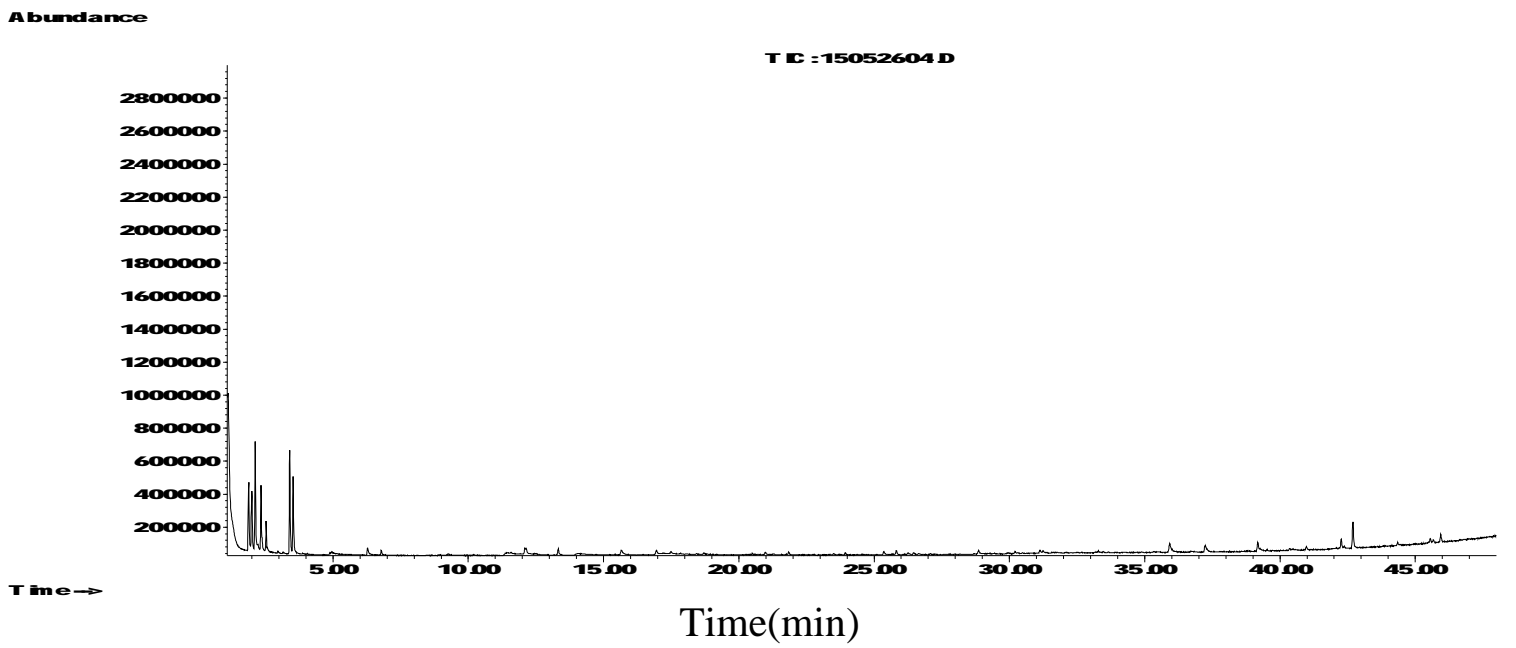

Fig3. TIC of volatile components extracted from fresh Musa nana Lour. flower.

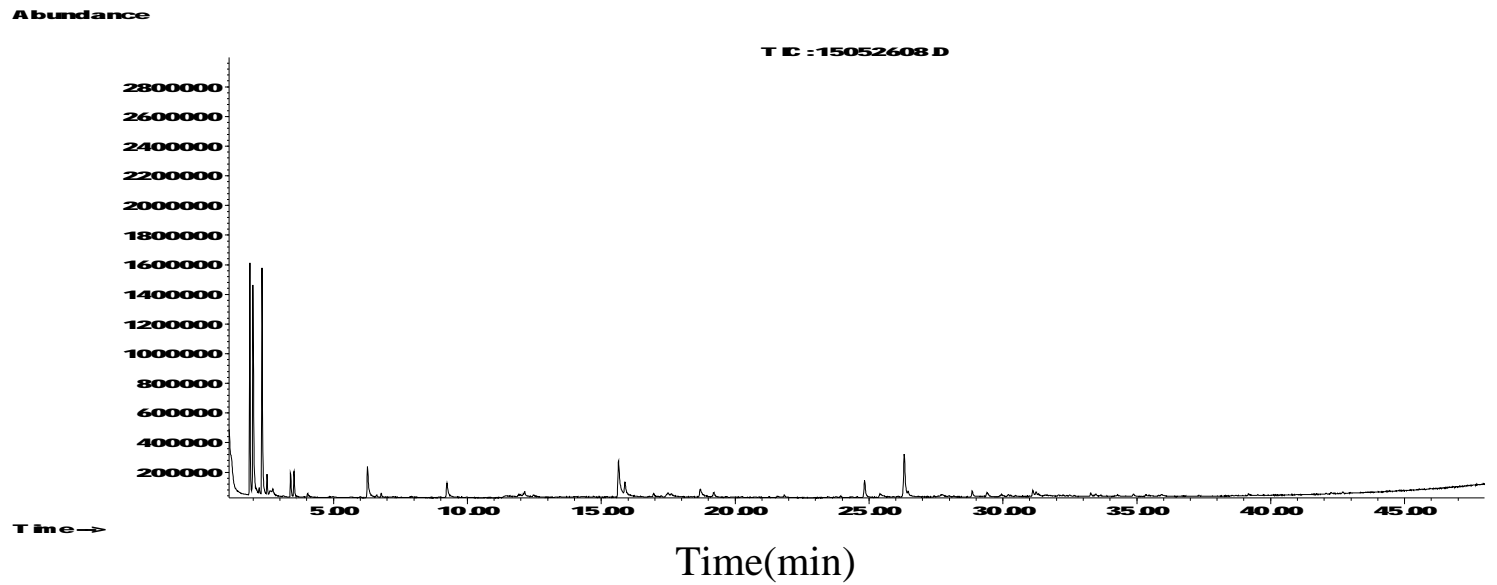

Fig4. TIC of volatile components extracted from Musa nana Lour. bract drying in the sun.

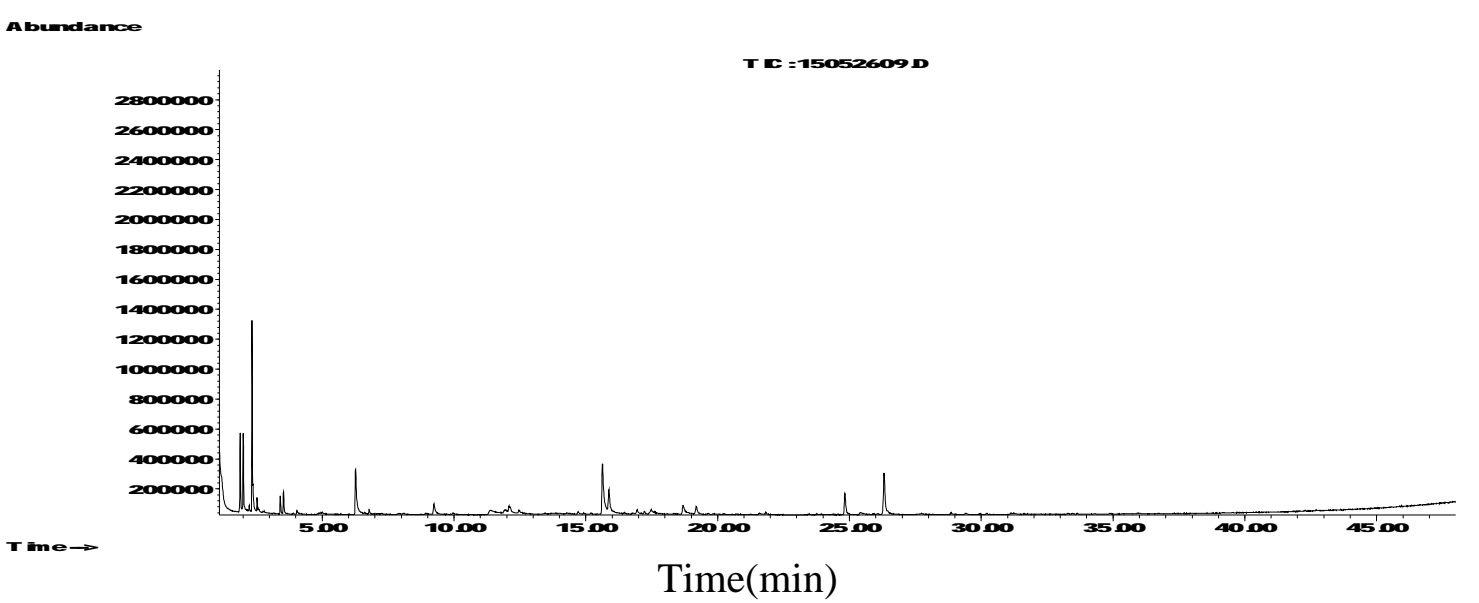

Fig5. TIC of volatile components extracted from Musa nana Lour. bract drying in the shade. 


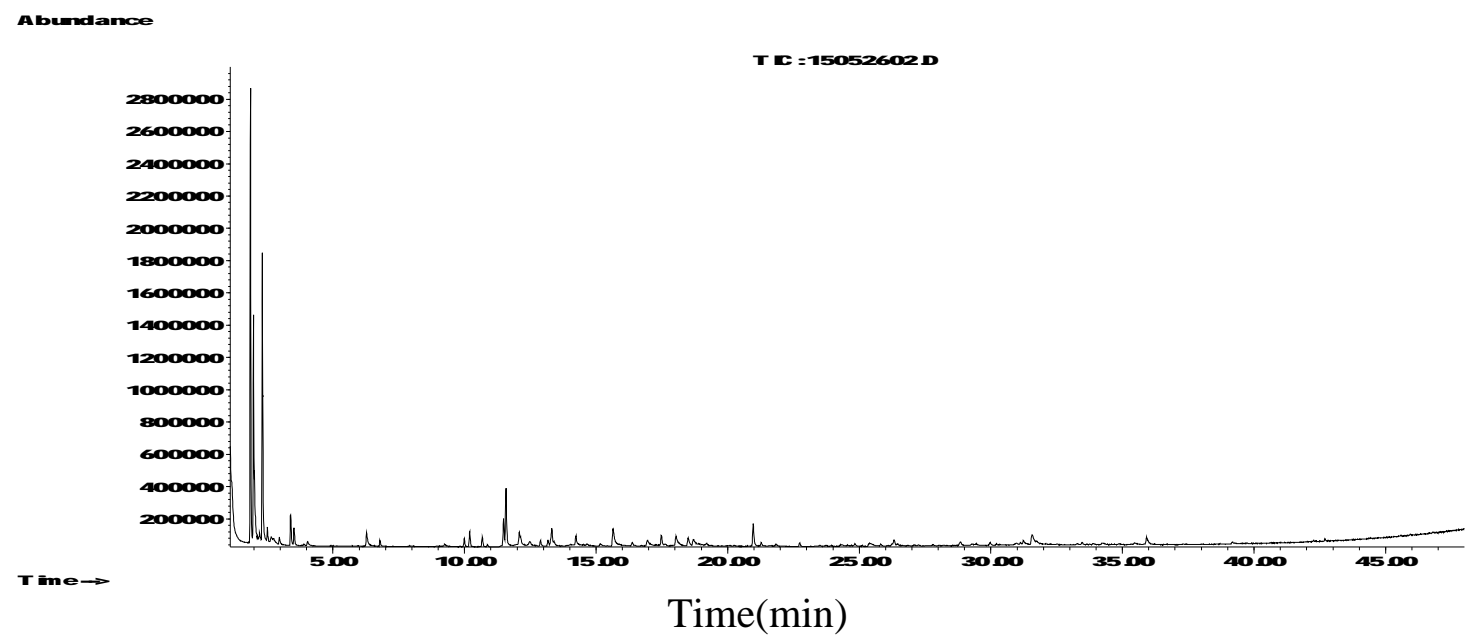

Fig6. TIC of volatile components extracted from fresh Musa nana Lour. bract.

Table1.Percentages of volatile components extracted from Musa nana Lour. flowers

\begin{tabular}{|c|c|c|c|c|c|}
\hline \multirow{2}{*}{\multicolumn{2}{|c|}{$\begin{array}{l}\text { Retention } \\
\text { time(min) }\end{array}$}} & \multirow[b]{2}{*}{ Compound } & \multicolumn{3}{|c|}{ Flowers' Percentage $(\%)$} \\
\hline & & & Fresh & sun & shade \\
\hline 1 & 2 & methanol & 9.424 & 17.771 & 23.301 \\
\hline 2 & 2.13 & ethyl alcohol & 14.187 & - & - \\
\hline 3 & 2.21 & acetone & - & 0.603 & 3.441 \\
\hline 4 & 2.34 & dimethyl sulfide & 7.079 & 8.679 & 3.518 \\
\hline 5 & 2.38 & methyl acetate & 1.276 & 1.397 & 2.362 \\
\hline 6 & 2.53 & 2-methyl-propanal & 2.932 & 5.611 & 2.936 \\
\hline 7 & 2.9 & 2-butanone & - & 0.358 & 0.406 \\
\hline 8 & 2.97 & ethyl acetate & 0.356 & - & - \\
\hline 9 & 3.16 & 2-methyl-propanol & 0.246 & 0.224 & 0.369 \\
\hline 10 & 3.4 & 3-methylbutanal & 13.878 & 13.437 & 7.585 \\
\hline 11 & 3.53 & 2-methylbutanal & 11.079 & 24.065 & 9.073 \\
\hline 12 & 3.89 & 2-pentanone & 0.164 & - & - \\
\hline 13 & 4.11 & pentanal & - & 0.199 & 0.158 \\
\hline 14 & 4.89 & 3-methyl-1-butanol & 0.332 & 1.373 & 4.056 \\
\hline 15 & 4.95 & (E)-2-methyl-2-butenal & - & 3.668 & - \\
\hline 16 & 4.96 & 2-methyl-1-butanol & 1.89 & - & - \\
\hline 17 & 5.72 & isobutyl acetate & - & - & 0.046 \\
\hline 18 & 6 & 1-octene & - & 0.243 & - \\
\hline 19 & 6.3 & octane & - & 0.116 & 0.11 \\
\hline 20 & 6.35 & hexanal & 2.034 & 8.86 & 6.178 \\
\hline 21 & 6.69 & 2-octene & - & 0.341 & 0.25 \\
\hline 22 & 7.02 & 3-cyclohepten-1-one & - & 0.06 & 0.067 \\
\hline 23 & 8.46 & 3-methylbutyl acetate & - & 0.419 & 0.43 \\
\hline 24 & 8.53 & 2-methylbutyl acetate & - & 0.381 & 0.259 \\
\hline 25 & 8.92 & 2-heptanone & 0.234 & 0.254 & 0.695 \\
\hline 26 & 9.25 & heptanal & 0.399 & 1.373 & 2.614 \\
\hline 27 & 9.99 & methyl caproate & - & - & 0.092 \\
\hline 28 & 10.2 & .alpha.-pinene & 0.221 & 1.373 & 0.105 \\
\hline
\end{tabular}




\begin{tabular}{|c|c|c|c|c|c|}
\hline 29 & 11.44 & benzaldehyde & 1.802 & 1.373 & 2.486 \\
\hline 30 & 11.59 & beta.-pinene & 0.205 & 0.11 & - \\
\hline 31 & 11.99 & $\begin{array}{c}\text { 6-methyl-5-hepten-2-on } \\
\mathrm{e}\end{array}$ & - & 0.111 & 0.766 \\
\hline 32 & 12.1 & 2-amylfuran & 1.081 & 0.413 & 1.386 \\
\hline 33 & 12.47 & octanal & - & 0.548 & 1.047 \\
\hline 34 & 13.33 & 1,8-cineole & 1.409 & - & - \\
\hline 35 & 14.1 & phenylethanal & 1.854 & - & - \\
\hline 36 & 15.66 & nonanal & 2.102 & 5.086 & 16.57 \\
\hline 37 & 17.49 & pinocarvone & 0.408 & 0.072 & 0.35 \\
\hline 38 & 18.7 & decanal & 0.391 & - & 0.788 \\
\hline 39 & 20.98 & .alpha.-fenchyl acetate & 0.601 & - & - \\
\hline 40 & 23.51 & .alpha.-copaene & 0.266 & - & - \\
\hline 41 & 23.94 & tetradecane & 0.5 & - & 0.074 \\
\hline 42 & 25.36 & Seychellene & 0.73 & - & - \\
\hline 43 & 25.44 & geranyl acetone & - & - & 0.116 \\
\hline 44 & 25.82 & aromadendrene & 0.864 & - & - \\
\hline 45 & 26.47 & pentadecane & 0.495 & - & 0.085 \\
\hline 46 & 27.25 & delta.-cadinene & 0.15 & - & - \\
\hline 47 & 28.86 & hexadecane & 0.798 & - & 0.226 \\
\hline 48 & 31.13 & heptadecane & 0.558 & - & 0.237 \\
\hline 49 & 31.25 & pristane & 0.299 & - & - \\
\hline 50 & 33.29 & octadecane & - & - & 0.105 \\
\hline 51 & 35.35 & nonadecane & - & - & 0.045 \\
\hline 52 & 35.93 & methyl palmitate & 2.865 & - & - \\
\hline 53 & 37.23 & ethyl palmitate & 2.304 & - & - \\
\hline 54 & 39.18 & heneicosane & 2.666 & - & - \\
\hline 55 & 40.98 & docosane & 0.573 & - & - \\
\hline 56 & 42.26 & (Z)-9-tricosene & 1.691 & - & 0.058 \\
\hline 57 & 42.7 & tricosane & 5.337 & - & 0.13 \\
\hline 58 & 44.35 & tetracosane & 0.472 & - & - \\
\hline 59 & 45.55 & Z-12-pentacosene & 0.667 & - & - \\
\hline 60 & 45.95 & Pentacosane & 1.438 & - & 0.103 \\
\hline
\end{tabular}

Table2.Percentages of volatile components extracted from Musa nana Lour. bracts

\begin{tabular}{cccccc}
\hline & Retention & & \multicolumn{3}{c}{ Bracts' Percentage(\%) } \\
\cline { 4 - 6 } No. & time(min) & Compound & Fresh & sun & shade \\
\hline 1 & 2 & methanol & 20.288 & 23.232 & 7.473 \\
2 & 2.21 & acetone & - & 0.521 & 0.547 \\
3 & 2.34 & dimethyl sulfide & 22.457 & 22.425 & 16.002 \\
4 & 2.38 & methyl acetate & - & - & 2.575 \\
5 & 2.53 & 2-methyl-propanal & 0.968 & 1.772 & 1.04
\end{tabular}




\begin{tabular}{|c|c|c|c|c|c|}
\hline 6 & 2.76 & 2,3-butanedione & - & - & 0.137 \\
\hline 7 & 2.81 & 2-butanone & - & - & 0.067 \\
\hline 8 & 2.96 & 2-methyl-3-buten-2-ol & 0.623 & - & - \\
\hline 9 & 3.15 & 2-methyl-propanol & - & - & 0.058 \\
\hline 10 & 3.4 & 3-methylbutanal & 3.124 & 2.457 & 2.183 \\
\hline 11 & 3.53 & 2-methylbutanal & 1.878 & 2.713 & 2.82 \\
\hline 12 & 3.89 & 2-pentanone & 0.231 & - & - \\
\hline 13 & 4.04 & pentanal & - & 0.369 & 0.58 \\
\hline 14 & 6.27 & hexanal & 2.267 & 5.363 & 10.79 \\
\hline 15 & 6.61 & (Z)-4-octene & - & 0.232 & 0.14 \\
\hline 16 & 8.95 & 2-heptanone & 0.106 & - & - \\
\hline 17 & 9.24 & heptanal & 0.351 & 3.137 & 2.583 \\
\hline 18 & 9.95 & methyl caproate & - & - & 0.356 \\
\hline 19 & 9.99 & .alpha.-phellandrene & 0.925 & - & - \\
\hline 20 & 10.2 & .alpha.-pinene & 1.68 & - & - \\
\hline 21 & 10.68 & camphene & 1.134 & - & - \\
\hline 22 & 11.41 & benzaldehyde & 0.128 & 0.771 & 2.916 \\
\hline 23 & 11.49 & sabinene & 3.146 & - & - \\
\hline 24 & 11.58 & .beta.-pinene & 6.95 & - & - \\
\hline 25 & 11.99 & 3-octanone & - & 0.593 & 1 \\
\hline 26 & 12.09 & 2-amylfuran & - & 0.244 & 0.998 \\
\hline 26 & 12.48 & octanal & 0.798 & 0.329 & 0.598 \\
\hline 28 & 12.89 & .alpha.-terpipene & 0.677 & - & - \\
\hline 29 & 13.17 & para tymene & 0.704 & - & - \\
\hline 30 & 13.32 & 1,8-tineole & 2.667 & - & - \\
\hline 31 & 14.23 & .gamma.-terpinene & 1.204 & - & - \\
\hline 32 & 14.7 & cis-linaloloxide & - & - & 0.448 \\
\hline 33 & 15.16 & terpinolene & 0.434 & - & - \\
\hline 34 & 15.65 & nonanal & 4.085 & 8.446 & 14.899 \\
\hline 35 & 17.48 & pinocarvone & 1.278 & - & - \\
\hline 36 & 18.04 & terpineol-4 & 2.049 & - & - \\
\hline 37 & 18.5 & myrtenal & 1.357 & - & - \\
\hline 38 & 18.69 & decanal & 1.321 & 2.337 & 2.655 \\
\hline 39 & 19.2 & .beta.-cyclocitral & 0.269 & 0.856 & 1.884 \\
\hline 40 & 20.97 & .alpha.-Fenchyl acetate & 2.893 & - & - \\
\hline 41 & 21.28 & dihydroedulan I & 0.4 & - & - \\
\hline 42 & 24.84 & .alpha.-ionone & 0.262 & 3.08 & 5.197 \\
\hline 43 & 25.41 & geranyl acetone & 1.183 & 1.286 & 0.968 \\
\hline 44 & 25.82 & Patchoulene & 0.211 & - & - \\
\hline 45 & 26.32 & .beta.-ionone & 1.009 & 8.289 & 11.009 \\
\hline 46 & 26.46 & pentadecane & 0.285 & 0.654 & 0.454 \\
\hline 47 & 28.85 & hexadecane & 0.64 & 0.829 & 0.37 \\
\hline 48 & 29.42 & .alpha.-Cedrol & - & 0.988 & 0.333 \\
\hline
\end{tabular}




\begin{tabular}{cccccc}
49 & 31.12 & heptadecane & - & 0.817 & 0.203 \\
50 & 31.24 & pristane & 0.468 & 0.634 & 0.155 \\
51 & 33.29 & octadecane & - & 0.4 & 0.11 \\
52 & 33.47 & phytan & 0.283 & 0.298 & 0.131 \\
53 & 34.89 & isobutyl phthalate & - & 0.427 & 0.145 \\
54 & 35.35 & nonadecane & - & 0.216 & 0.053 \\
55 & 35.96 & methyl palmitate & 1.323 & 0.421 & 0.234 \\
\hline
\end{tabular}

\section{Conclusions}

Banana flowers were usually discarded after banana fruit ripening, including banana bracts, which leaded to resource waste and environmental pollution. In this paper, 43, 29 and 39 components were identified in fresh, sun-dried and shade-dried Musa nana Lour. flowers, respectively. The identified volatile components in this project are more than those in banana bud[7], which may be due to they used the different extraction methods. The essential oil composition and content of Musa nana Lour. flowers and bracts had changed after drying. This situation also appeared in the analysis of essential oils in the fresh and dry banana bud[7]. The first reason may be the original chemical composition in fresh flower and bract derived from other volatile compounds by oxidation and other reactions during the drying process, and the second probability is that volatile components are volatilized or converted to other compounds during the drying process. The compositions and contents of Musa nana Lour. flowers and bracts volatiles changed significantly during the drying process. Improving the utilization of the banana(Musa nana Lour.)flower and bract can not only protect the environment but also reduce the waste of resources. The results of this article provides fundamental information for the further development and utilization of Musa nana Lour. flowers and bracts.

\section{Acknowledgements}

This work was supported by the Special Funds of Outstanding Young Scientists in Guizhou, PR China (2013, NO.46), and Miao Nationality Medicine Research Synergy Innovation Center Project (Grant No . Qian Jiao He Xie Tong Chuang Xin Zi [2015] 05th). The authors thank the government of China for their financial support.

\section{References}

[1] Wickramarachchi, K.S.; Ranamukhaarachchi, S.L. Science Asia,2005.31:265-271.

[2] Grover, J.K.; Yadav, S.; Vats,V. Journal of Ethnopharmacology, 2002, 81(1): 81-100.

[3] Dhanabal, S.P.; Sureshkumar, M.; Ramanathan, M. Journal of Herbal Pharmacother-apy, 2005,5(2):7-19.

[4] Pari, L.; Maheswari, J.U. Journal of Ethnophar-macol 1999, 68 (1/2/3) :321-325.

[5] Pari, L.; Maheswari, J.U. Phytotherapy Research, 2000, 14(2): 136-138.

[6] Lin,D.Q.; Lin,C.S. Science \& Technology Information,In Chinese, 2006, 18(4): 12-14.

[7] Qiu,H.; Li,Y. K.; Xie,Y.X. Journal of Agriculture,In Chinese,2015,5(9):87-90. 